\title{
Retainment and retrenchment of employees in the education sector in India in comparison to FMCG sector during COVID 19
}

\author{
Kamalika Bhattacharya*(MBA 1st year, NSHM Knowledge Campus Durgapur), \\ Amrita Bhattacharya (Assistant Prof. Department of Management Studies, NSHM Knowledge Campus \\ Durgapur).
}

\begin{abstract}
The COVID 19 pandemic has had an impact on every sector around the world. To combat this situation lockdown was imposed on March 25, 2020 which has adversely affected various job sectors though out the country. It is found that the education sector has been fighting to survive the crisis with a different approach and digitising the challenges to wash away the threat of pandemic. The FMCG sector has also suffered a great deal as labourers have moved to their native places due to coronavirus pandemic. Private sectors saw more modular curves in the process than the government sector jobs. The paper reviews and studies the impact of this pandemic on employees of education sector and FMCG sector. It highlights the comparison between these effects (i.e. the retainment and retrenchment of employees) of these two sectors.
\end{abstract}

KEY WORDS: COVID 19, Employee retainment, Education sector, FMCG sector.

\section{Introduction}

This COVID outbreak primarily being a human tragedy has affected thousands of people. Many countries went under lockdown, restricting their economic agents and stopping the mobilization process between different countries and within. Globally it had a rising impact on economy taking this health crisis tumbling into economic crisis because of restriction mobility of labour, volatility in stock market, cancelation of flights and train thus blocking any long route transportation, fall in oil prices and many more. A great percentile of India's population consists of below average earners. A study on poverty estimates in India shows that an estimation of 150 - 199 million people has additionally fallen under poverty in 2021 - 2022; majority being from rural areas, due to its tendency to become impoverished. This article contains a thorough discussion about its effect on employees in the mentioned two sectors. Employee retention or retainment of employees refers to the organization's potential to retain its employees that is to keep employees motivated and focused 
so they elect to remain employed and fully productive for the benefit of the organization. Statistical analysis shows that an $80 \%$ retention rate means that $80 \%$ of the employees of an organization were constant in a given period of time. This is achieved by a process of encouragement for the employees and showing them or rather providing them with such a culture code that shows transparency and enhance employee morale so in turn retaining them and encouraging them to have long term bonding with the company. Clan culture and adhocracy culture type of approaches were brought in and practised more regularly in order to achieve highly collaborative and flexible working environment. When we talk about this teaching profession in particular, passion knows no boundaries. Teachers may go above and beyond the regular cell of their duty in order to bring about a positive change in their students attitude and betterment of their life. Data shows a $13 \%$ increase in this profession in the last 4 years, the average turnover being 27.25 over 5 years there is still an urgent need to recruit qualified professionals to complete the gap. While in case of FMCG the scenario in hand shows honourable Finance Minister, Smt Nirmala Sitharaman announced an outlay of INR 1.97 Lakh Crores for the Production Linked Incentive (PLI) Schemes across 13 main sectors. so as to create more employment opportunities. Government of India has further introduced 10 new PLI schemes in November 2020. Leading FMCG companies have termed the PLI scheme approved by the government for the food processing sector as a game-changer which would help bring more investment. The idea behind this was to help create more jobs in the sector, ensure the availability of a wider range of valueadded products for consumers and the Indian companies to establish themselves in the foreign markets. The basic need to retain the employee comes from the underlying expenses an organization has incurred on their recruitment and huge amount it has invested on each employee for giving training to shape them to be fit for the organization and to improve the efficiency of the employees, so it is the obvious expectation of the organization to make use of these outcome for its development. Some organizations have identified the problems behind turnover and trying to manage in order to retain the talents by addressing the factors influencing over these. In order to confront the problem and take control over attrition of employees, organizations are making policies and framing strategies with HR managers with respect to recruitment, selection, induction, training and development, compensation and benefits, designing job, evaluation of job and wage standards etc., in order to enhance the duration of the employees in an organization. 


\section{Retrenchment due to COVID - 19}

In private sectors corporates terminates employees who fail to meet the performance standards of the company, do not follow the company's moral and ethical code of conduct or fail to work with their team. These procedures are often carried out abruptly by the HR department of a company considering various under lying reasons, or to cut down expenses. Retrenchment is one of these ways companies used by the company terminate employees in order to downsize. Subsidiary companies of Multinational Corporations mostly settles for retrenchment to control their expenditure. However, they fail to consider the legal requirements to be carried out along with this process.

One of the main causes of retrenchment can be due to the surplus of labour or inability of employees to match the performance standards as required by the company. The Industrial Dispute Act, 1947 deals with employment-related disputes in India and Section 2 of the Act states that 'retrenchment means termination of service of a workman by an employer for any reason whatsoever, otherwise than as a punishment inflicted by way of disciplinary action.

The COVID-19 pandemic has resulted in a widespread layoffs that have led to a substantial percentage of the workforce being unemployed. The decrease in employment can be ascribed to the effects of the illness and efforts to contain the virus. The number of unemployed people who reported for being laid off temporarily was more than doubled in March. The number of permanent job losers increased by 177,000 to 1.5 million. The number of unemployed people who were jobless in less than 5 weeks increased from 1.5 million in March to 3.5 million, counting for almost half of the unemployed.

The effect of COVID-19 on the population has been grave irrespective of race, educational qualification, financial status or sex, however same cannot be said for its repercussions which have affected the vulnerable the most. The lockdowns as a reaction to COVID-19 have disrupted conventional schooling with nationwide closures in almost all educational organizations, lasting at least 10 weeks. While the academic community have made great efforts to ensure that there is no hindrance in learning or educational growth of the population, children and students have had to be more dependent on their own resources to continue learning remotely through the Internet, television or telephonic calls. Teachers also had to adapt to new tweedy concepts and modes of delivery of teaching, for which they may not have been prepared or trained. 


\section{Significance of Retention}

Retention of workforce evaluation refers to employee's ability to not only absorb and retain training or specialized skills and to apply these skills to their job. While the word employee retention means the rate at which a company can keep long term employees. It is majorly about promoting jobs. The main strategies involved is a combination of promoting job satisfaction and respectful treatment, fair compensation, a sense of mutual trust, job security and identifying the right way to use their unique skill. It is to encourage a healthy work-life balance. It is seen that unhappy employees are less productive and hence more likely to result in turnover. Retaining their best employees comes under the responsibility of the employers and can be done by various rewards like Compensation, support system, a better work environment, promotions and growth. One of the major factor of this theory is to ensure job satisfaction. This includes job satisfaction in times of need, various intrinsic factors of job satisfaction, employee self-efficacy and many other motivational factors. In order to achieve an effective employee retention the employers need to create and make prevail an environment that is in agreement with the above mentioned and many other factors. A strong retention strategy is a powerful recruitment tool. Retention of key employees plays a critical role in the long-term health and success of any organization. Being able to hold back your best employees is important as they already have deeply embedded organizational knowledge and the required learnings this can ensure customer satisfaction, increase in sale value, happy colleagues as they have already built an understanding and cooperating environment within them, effective succession planning Hence failing to do so can be a big loss for an organization. Calculated data shows that losing an employee that plays a key role in the organization can sum up to five times of his CTC. Intelligent employers always realize the importance of retaining the best talent. Retaining talent has never been so important in the Indian scenario; however, things have changed in recent years.

Due to abrupt loss of jobs and ascending scale up in debts a huge number of employees all over the country are getting unsatisfied. The Human Resource (HR) is recently focusing on the retention of their employees professionally. They are taking a lot of measures and strategies into consideration. Thus this retention played an important role as far as curbing the adverse impact of COVID-19 when financial loss and gain is considered. 


\section{Impact on FMCG sector}

The corona virus pandemic has created a panic in the market and almost nothing remains untouched by it. Like previously mentioned it has its grasp on all including FMCD, insurance, finance, FMCG etc. The COVID-19 has led us to a worldwide recession in FMCG sector. It has already developed economic environment across the world that are hinting at the next global crisis, impacting over 195 countries worldwide. IN order to curb the disease countries across the globe are taking aggressive measures one of it majorly being social isolation.

This social isolation in return has been the major killjoy for employment. Malls, retail shops and many other outlets, departmental stores being the major market for FMCG goods were closed down in duration nullifying the need of employees and workers. Hence taking a toll on employment. The companies in order to meet their financial loss has sacked a percentage of workers.

\section{Impact on Education Sector}

The COVID - 19 has thrust higher education into unchartered water with challenges impacting all facets of the institution. While each one of us had to learn and unlearn to adjust ourselves into this new way of work life balance, faculty members in particular have faced significant disruption. According to a nationwide survey conducted by 'Chronicles of higher education' more than half of the faculty members are considering retiring or changing careers and leaving higher education, with tenured faculty members even more likely to retire than others. This has forced all the educational institutes to re-evaluate the ways of education delivery system.

Companies have made sure that the faculty and staff members have the resources and support if not the same was provided immediately, that was needed to perform their jobs safely and efficiently. We can hands down say this sector being the most that has been able to produce job security and retain their employee thus reserving their talents in midst of this pandemic. 


\section{Methodology}

\section{Search Strategy:}

The literature search was conducted mainly through Google Scholar, Scopus and DOAJ databases. The articles published in English language in the time period from 2019 to 2022 were selected for the present review. The descriptors used for the literature search were

"Employee Retention", "Impact of COVID - 19", "attrition rate in different sectors due to COVID ", "Impact of COVID on India's Economy", "Effect of COVID on education sector", "COVID and FMCG sector" and "Employment in education sector versus FMCG sector".

Boolean words such as 'OR' and 'AND' were used to complete the literature search. In the initial search, a total of 70 documents were obtained. Furthermore, the lists of articles obtained were later manually screened to identify the relevant studies to address the present study's objective and categorize the articles based on various other impact of this pandemic.

\section{Discussion and Conclusion}

There was a total of two different objectives that included in the same assessment. The first one is about exploring the impact of COVID-19 on employment. From the analysis, it is found that there are no sectors untouched by this. This pandemic has left its permanent mark on the working population of the country. The article demonstrated that Access of Information and updates on Pandemic and Financial Benefits are the most valuable factors that increase the retention level of the employees. In terms of the current issues of Covid-19 Pandemic, most of the respondents identified it as major economic problems in all over the world due to which job layoffs increased. It has been that communicating with the employees from the management and informing them about the Pandemic and intensity could be ideal for the employees to get satisfied and retain with the company accordingly. Secondly it studies this effect in the education and FMCG sector. It is found that the education sector along with the IT sector has reacted most efficiently against this situation and retrenchment rate is much lower as compared to the FMCG sector.

Digitalization has played a great role in this. Various employee retention techniques has been taken into consideration by different organization, many strategies planned and played out by HR departments to increase retention and decrease the attrition rate. 


\section{REFERENCES}

1. Ashraf Saeed Elsafty, Mohammad Ragheb. The Role of Human Resource Management Towards Employees Retention During Covid-19 Pandemic in Medical Supplies Sector - Egypt. scholar.google.co.in/scholar?q=covid+and+retention\&hl=en\&as_sdt=0\&as_vis=1\&oi =scholar

2. Dr. Fredrik Jorgensen, Kenneth Kwame AZUMAH. Employee retention strategies: the case of a patent firm in Australia.

3. Dr. Ruchi Tripathi, Dr Vinay Pratap Singh. A Study on Employee Retention in Education Sector in India (with special reference to Noida Region)

4. Dr. Pravat Kumar Jena. Impact of pandemic Covid - 19 on education in India.

5. George J. Borjas, Hugh Cassidy. The adverse effect of the Covid - 19 labour market shock on immigrant employment.

6. Krishna Ram, Shivani Yadav. The impact of Covid - 19 on poverty estimates in India: A study across Caste, Class and Religion.

7. Manju Dhillon. Employee Retention - A real time challenges in Indian IT Sector

8. Manish Kumar Singh, Yadawananda Neog. Contagion effect of Covid - 19 outbreak: Another recipe for disaster on Indian economy.

9. M.S Kamalaveni, S. Ramesh, T. Vetrivel. A Review of literature on employee retention.

10. The Chronicles of Higher education. Fridelity Brokerage Services LLC. "On the verge of burnout" Covid - 19's impact on faculty and career plans.

11. Yogesh Mahajan. Impact of coronavirus pandemic on fast moving consumer goods. (FMCG) sector in India. 